Environment Conservation Journal 14(3) 41-45, 2013

ISSN 0972-3099 (Print) 2278-5124 (Online)

Abstracted and Indexed

\title{
Some updates with successful first breeding report of Great Indian Bustard from Vidarbha region, Maharashtra
}

\author{
G. A. Wagh $\otimes^{1,3}$ and J. S. Wadatkar ${ }^{2,3}$
}

Received: 05.01.2013

Revised:13.04.2013

Accepted: 15.06.2013

\begin{abstract}
Great Indian Bustard (GIB), Ardeotis nigriceps is a threatened bird species and listed as critically endangered. Presently, GIB is found only in six states of India i.e. Rajasthan, Madhya Pradesh, Gujarat, Maharashtra, Andhra Pradesh and Karnataka. During the last 20 years the GIB population has crashed in many areas and presently the population could be as low as 500 birds in India. In Maharashtra, as per survey conducted during 2005-06, about 30 to 36 GIBs were counted. Out of these, 08 birds were reported from Chandrapur and Nagpur districts in Vidarbha region. Habitat of the GIBs in Chandrapur district is cultivated agriculture lands and grasslands around villages. During 2010-11, conducting regular visits, continuous monitoring and collecting information from foresters, local people we documented a breeding report of GIB from Vidarbha region. Total four nests were sighted in Warora and Bhadrawati talukas of Chandrapur district. Each nest contained a single egg. Out of these four nests, hatching took place in only two nests but only one chick survived; in the third nest the egg did not hatch for 40 days while at the fourth nest the egg was accidentally broken. So, immediate protection to nesting sites is required.
\end{abstract}

Keywords: Ardeotis nigriceps, breeding, critically endangered, great Indian bustard, Vidarbha

\section{Introduction}

The Great Indian Bustard Ardeotis nigriceps (GIB) is endemic to Indian sub-continent and found only in some parts of Gujarat, Maharashtra, Rajasthan, Karnataka, Andhra Pradesh and Madhya Pradesh states. The respective state Governments has declared the sanctuaries for the GIB. According to Rahmani $(1987,2012)$ their population has declined to almost $50 \%$ during the last $10-15$ years. As per Dutta et al. (2010), today the total population has been estimated to be about 300 individuals only (Rahmani, 2012).The Great Indian bustard is a threatened bird species and is listed in schedule - I of the Wildlife Protection Act, 1972 (India), and it is classified as critically endangered in the IUCN Red list 2011, and the Bird Life International has also classified it as critically endangered in the Red Data Book 2011.In India, the Great Indian Bustard is protected in 12 Sanctuaries in few States. Nannaj Great Indian Bustard Sanctuary in Maharashtra

Author's Address

${ }^{1}$ Shri Shivaji Science College, Amravati

Email: gajuwagh252424@rediffmail.com.

${ }^{2}$ S. G. B. Amravati University, Amravati

Wildlife \& Environment Conservation Society,

${ }^{3} 42$, Greenpark colony, Shegaon road, Amravati

Email: jayant.wadatkar@yahoo.co.in

Copyright by ASEA

All rights of reproduction in any form reserved is one of them. Unfortunately, the GIB population is continuously declining in Nannaj sanctuary; the causes could be mismanagement, industrial pressure, human encroachment, expanding agricultural fields, urbanization, over-grazing and poaching. Recently, on $28^{\text {th }}$ July 2011, Maharashtra Government denotified some part of Nannaj sanctuary and the Government has kept only 1200 sq. kms protected area for the GIB. However, in Vidarbha region (East Maharashtra) the existence and regular sightings of the Great Indian Bustard in Chandrapur district comes as some good news for bird conservationists. According to Thosar et al. (2010), the GIB population in Vidarbha is just eight birds. In 2011, the authors also sighted eight GIBs in Warora and Bhadrawati talukas of Chandrapur district and recorded their breeding sites. Hereby, we present some updates about the status, the distribution, the ecology and the observation of the nesting sites of GIB in the Chandrapur district of Vidarbha region.

Study Area:

Chandrapur district is situated on the eastern side of Maharashtra state and famous for its wildlife and 
coal mines. Well known Tiger Reserve "Tadoba Andhari" is situated in the central part of the district, while the habitat of GIB is situated on the western side of the tiger reserve which is unprotected. This area comes under the basin of the Wardha river. Marda, Wanoja and Bhatadi $\left(33^{\circ} 52 " \mathrm{~N}\right.$ and $\left.75^{\circ} 43^{\prime \prime} \mathrm{E}\right)$ are the villages of Chandrapur district where the GIBs are located and breed in cultivated fields. This area is about $3 \mathrm{~km}$ away from Warora town in Chandrapur district of Vidarbha (MS). Warora is located on the Nagpur Chandrapur state highway (Fig1). Marda, Wanoja and Bhatadi have cultivated fields with variety of crops like cotton (Gossypium arboreum), Soyabeen (Glycine max), Toor (Cajanus cajan), lakholi (Lathyrus sp.), Pea (Pisum sativum), Wheat (Triticum vulgare), Jawas (Oriza sativa), Sambar (Coriandrum sativum), Chana (Citer sp.) (Fig 2.), surrounded by wastelands with shrubs, herbs, grasses, climbers, Babul (Acacia spp.) and trees. According to the local people the GIB is a regular visitor to this area since their childhood and feeds mainly on insects and pests of the crops. This bird species is well known to the villagers as a "Hoom" after its unique call.

\section{Material and methods}

The status, distribution and the breeding study of the GIB were carried out for one year from May 2010 to May 2011 in Chandrapur district (MS). GIBs were observed through Nikon binoculars (50 $x$ 10) and their existence, breeding behavior and nesting sites were documented with Nikon D90 Camera and $80-400 \mathrm{~mm}$ Zoom lens. Locations of sighted Great Indian Bustard and their nesting sites were marked by GPS.We conducted interviews with several villagers, land holders and forest staff to obtain information about the past existence, the feeding habit as well as the breeding sites of the GIB. Available literature related to GIB was reviewed and compiled. The Great Indian Bustards were counted by walking on the margin of crop field of the Wanoja-Marda area of Warora taluka and Bhatali area of Bhadrawati taluka.

\section{Results and Discussion}

On $6^{\text {th }}$ December, 2010 during our survey, total eight GIBs were sighted. Out of these eight GIBs, two were sighted in Bhatali area of Bhadrawati taluk, four birds in Wanoja area (two males \& two females) and two in Marda area of Warora taluk

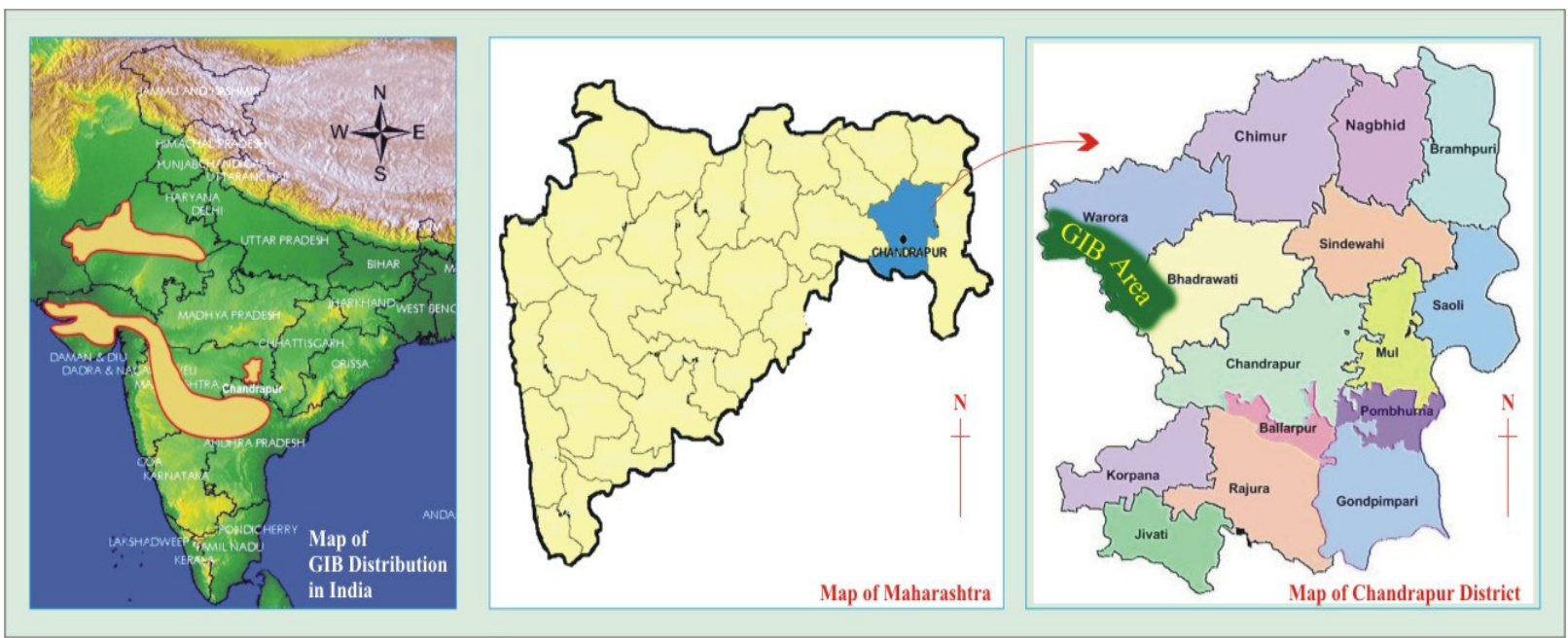

Fig 1: GIB distribution range in India and Chandrapur District in Vidarbha Region of Maharashtra

(one male \& one female). All these birds were mating on the same day in Wanoja area (Fig. $3 \mathrm{c}$ sighted in cultivated fields (Fig. 3 a). We also and d). Some of the remarkable things that are observed one male GIB with an inflated gular observed these GIB's were very much sensitive to pouch fluffy white feathers and the tail was held outsiders but they show familiarity with the local cocked up over the body to attract female for villager and farmers (Fig. 3 b). 


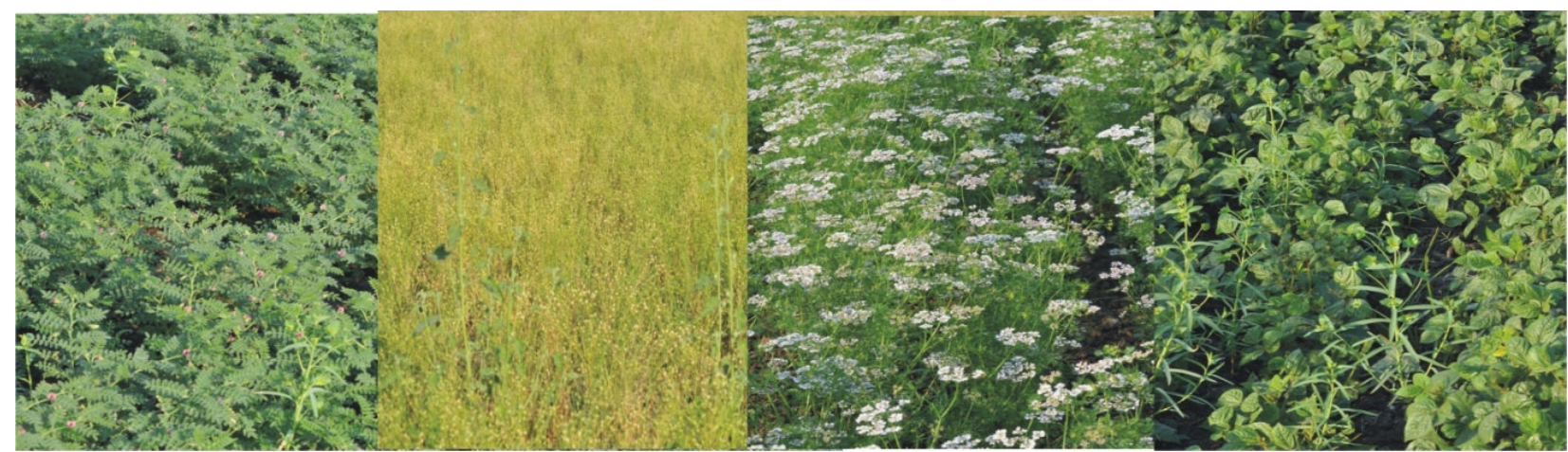

\section{Chana (Citer sp.) Jawas (Oriza sativa) Sambar (Coriandrum sativum) Soyabeen (Glycine max)} Fig. 2: Mixed cultivated crop pattern in the study area

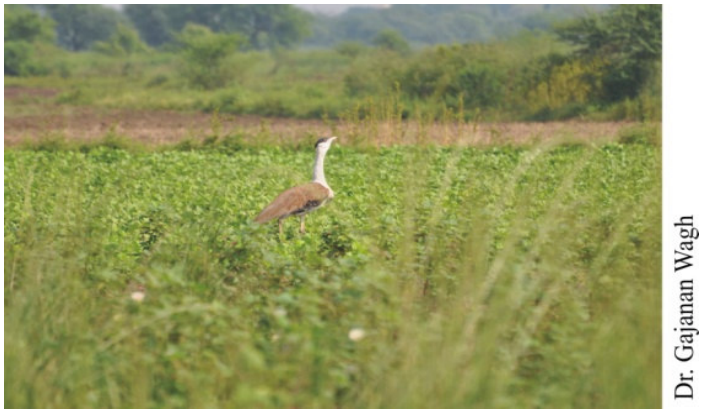

Fig. 3 a. GIB (Male) sighting at Wanoja

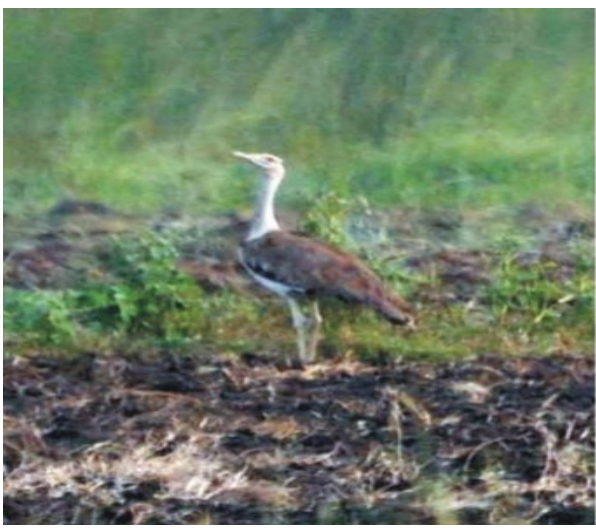

Fig. 3 c. GIB (Female) at Marda

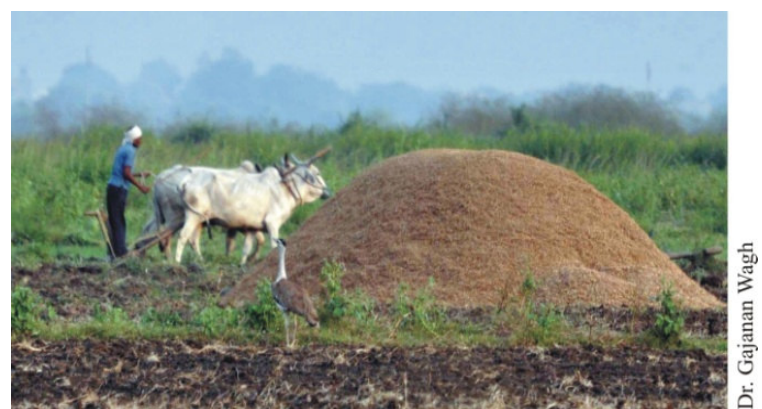

Fig. 3 b. GIB \& farmer friendship association at Wanoja

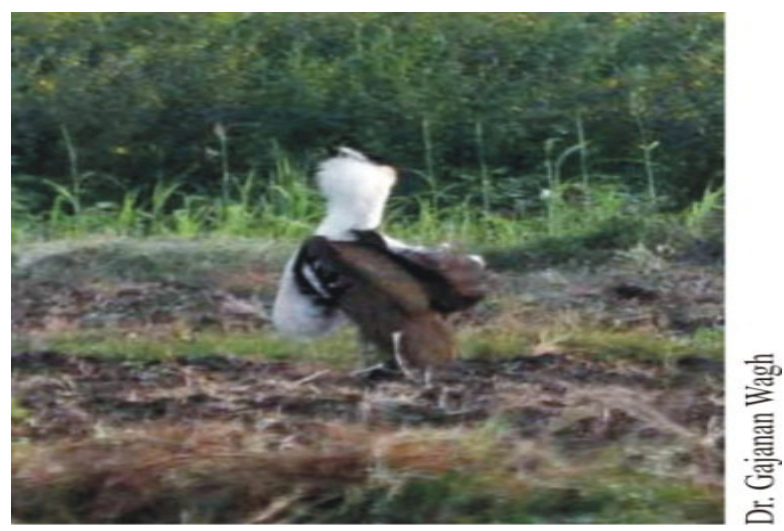

Fig. 3d. Male in displaying at Marda
On the $23^{\text {rd }}$ January 2011, the author's recieved the information of breeding of the GIB from Wanoja and Marda from a local informer and the authors confirmed this information from the Warora range Forest department. After that immediately we carried out the survey of the nesting sites of GIB in Bhatali, Wanoja and Marda area.During the survey, we visited three nesting sites along with the local informer in Wanoja and Marda area, one nesting site in Bhatali area could not be visited on the same
day.Observations of the nesting sites were documented while keeping safe distance and without disturbing GIB female. During day time the female could not attend the nest for incubation due to farmland activities. But in the evening by about 5 p.m. females came back to the nest and would incubate during the night.

\section{Nesting Site 1:}

First nesting site was located in the open space in farmland which was surrounded by the cotton crop. 
This site was about a $\mathrm{km}$ away from the Wanoja Village on the South. Nest was a simple depression on an open ground with only one egg.

\section{Nesting site 2:}

Second nesting site was located in the Jowar crop at Wanoja. This site was about 500 meters away from first nesting site towards the South. There too single egg was found which was smaller than the first egg.

\section{Nesting site 3:}

Third nesting site was located in the cotton crop near Marda village. This site was approximately 2 kms away from first and second sites. This nest also had a single egg.

\section{Nesting site 4:}

Fourth nesting site was located in Jowar crop near the Bhatali village in Bhadrawati taluk, here also nest had a single egg.

In the month of March 2010 we again conducted the survey in GIB's area, we also had received the information about the breeding status from the villagers and the local forest staff. According to their information, at two sites (nesting site 1 and nesting site 2) in the Wanoja area successful hatching took place, but unfortunately only one chick could survive and the other died. At the third site (nesting site 3) in the Marda area the egg did not hatch up to 40 days due to unknown reasons, while at the fourth site (nesting site 4) in Bhatali area the egg was accidentally broken.

\section{Threats to the GIB:}

1. Proposed and ongoing thermal power projects and coal mines.

2. Ongoing developmental works of pipeline and canal digging.

3. Increasing industrial pressure on land.

4. High tension electric line network.

5. Increasing atmospheric temperature due to existing thermal power projects.

\section{Threats to the nesting sites of the GIB:}

1. Disturbances from local farmer's activity.

2. Daily farm worker activities.

3. Grazing.

4. More use of insecticides and pesticides by farmers to control pests.
5. Lack of awareness among locals about breeding of the GIB.

\section{Conclusions}

The GIB generally breeds during the period of March to September in most of the areas of India (Ali, S., 1996) and as per the observations we observed the breeding period of the GIB in our study area during November to March. Such early breeding of GIB in this area is due to availability of food and shelter. After rainy season from the month of October, most of the cultivated land of this area is covered by variety of crops and non cultivated land is covered by tall grass, herbs and shrubs which attract the various species of insects so the GIB gets benefit of shelter, food and hiding place too.

One successful hatching report from Chandrapur district was the first breeding record of GIB in Vidarbha region of Maharashtra is good news. But out of the four nesting sites at only one site successful hatching took place. Such a low success rate of hatching in this area may be due to a number of reasons, such as, disturbances from the local farmers, farm activities, grazing, use of insecticides and pesticides in the farms and lack of awareness among the locals about the breeding of the GIB.

So for the conservation of the GIB nesting sites, we have the following suggestions to make.

1. Immediate protection to nesting sites should be provided.

2. To form the GIB friend groups from among the local people.

3. To inform the forest department about the nesting sites.

4. To monitor the nesting sites by the forest department staff, upto hatching time.

5. Disallow the farming and grazing and visitors in the nesting sites.

6. To provide compensation to the farmer for non farming area due to the nests.

7. To avoid spraying of insecticides on crops near the nesting site.

\section{Acknowledgment}

We are thankful to forest officials of Warora Range and farmers of Marda, Wanoja and Bhatali villages for their kind support and for providing the necessary information. 


\section{References}

Ali, S. 1996. The Book of Indian Birds. Bombay Nat. Hist. Soc. Rahmani A. 2012. Threatened Birds of the India : their Mumbai. Pp. 21 \& 135.

Dutta, S., Rahmani, A.R., and Jhala, Y.V. 2010. Running out of time? The great Indian Bustard Ardeotis nigriceps status, viability, and conservation strategies. European Journal of Wildlife Research. Published online.on DOI 10.1007/s10344-010-0472-Z

Rahmani A. 1987. The Great Indian Bustard. Bombay Nat. Hist. Soc. Mumbai Pp.1-24. conservation requirement. Oxford University Press. Pp.180-190.

Thosar G., Ladkhedkar R., Pimplapure A. and Kasambe R. 2007. Status and conservation of Great Indian Bustards in Vidarbha. Mistnet. 8 (3): 10-11.

Thosar G., Ladkhedkar R. and Pimplapure A. 2010. Great Indian Bustard (GIB) in Vidarbha - an update 2005-2009. Mistnet. 11 (3): 7-9. 